\title{
Emotional Impact of Long Term Chronic Obstructive Pulmonary Disease
}

\author{
Talha Saad ${ }^{1}$ Jyoti Tiwari ${ }^{2}$ Wahid Khan ${ }^{3}$ Jamal Akhtar $^{4}$ Rahul M Deo ${ }^{5}$ \\ ${ }^{I}$ Dept of Tuberculosis and Chest Diseases, Bundelkhand Government Medical College Sagar, MP, \\ ${ }^{2}$ Dept of General Medicine, Bundelkhand Government Medical College Sagar, MP, \\ ${ }^{3}$ Dept of Internal Medicine,Royal Court AffairsHospital,Muscat, Oman \\ ${ }^{4}$ Dept of Tuberculosis and Respiratory Diseases,Aligarh Muslim University,Aligarh \\ ${ }^{5}$ Dept of Psychiatry, Bundelkhand Government Medical College Sagar, MP,
}

\begin{abstract}
:
Background: Although it has been repeatedly suggested from western studies that chronic obstructive pulmonary disease (COPD) is associated with lot of emotional impact. A study was undertaken to investigate whether depression occurs more often in patients with COPD than in controls. The demographic and clinical variables associated with depression were also determined.

Methods: Patients with a registered diagnosis of obstructive airway disease in general practice, aged $\geq 40$ years, forced expiratory volume in 1 second $\left(F E V_{l}\right)<80 \%$ predicted, FEV $V_{1}$ reversibility $\leq 12 \%$, FEV $/ V C \leq$ predicted $-1.64 \times S D$, and a history of smoking were selected. A random sample of subjects without a registered diagnosis of asthma or COPD aged 40 years or older acted as controls. Depression was assessed using the Centers for Epidemiologic Studies Depression (CES-D) scale.

Results: In patients with severe COPD (FEV $<55 \%$ predicted), the prevalence of depression was $25.0 \%$ compared with $17.5 \%$ in controls and $19.6 \%$ in patients with mild to moderate COPD. When the results were adjusted for demographic variables and comorbidity, the risk for depression was 2.5 times greater for patients with severe COPD than for controls (OR 2.5, 95\% CI 1.2 to 5.4). In patients with mild to moderate COPD this increased risk of depression was not seen. Living alone, reversibility of $F E V_{1} \%$ predicted, respiratory symptoms and physical impairment were significantly associated with the scores on the CES-D scale.

Conclusion: Patients with severe COPD are at increased risk of developing depression. The results of this study underscore the importance of reducing symptoms and improving physical functioning in patients with COPD.
\end{abstract}

\section{Introduction}

COPD, defined as not fully reversible air-flow obstruction ${ }^{1}$ is now the fourth leading cause of death in the world ${ }^{2}$. Among the many aspects of COPD, depression is a serious concern, because it is generally associated with longer hospitalization, poor survival rate, and impaired physical and social functioning ${ }^{3}$.Patients with depression also characteristically make fewer attempts to improve their health ${ }^{4,5}$. Therefore, examining symptoms of depression is an important part of comprehensive COPD treatment.

Anxiety is defined by a feeling of indefinable insecurity, which characterizes the psychological component of anxiety disorders. Depression, which comes from the Latin depressio meaning "press down", denotes an illness for some or a syndrome for others, whose central manifestation is a mental state characterized by marked lassitude, reduced self-esteem and pessimism. These disorders are common in COPD, anxiety and dyspnoea are closely linked, and depression is more frequent in COPD than in other chronic diseases.

One study suggested that the first hospitalization for COPD occurs sooner in patients with concomitant anxiety and/or depression. One hypothesis is that dyspnoea might be perceived more intensely and earlier in these patients ${ }^{6}$.

Similarly, proven airway obstruction is associated with a higher frequency of generalised anxiety disorder or panic disorder ${ }^{7}$.Depression affects between $20 \%$ and $60 \%$ of COPD patients depending on the study, COPD stage and the scale used ${ }^{8}$. The mortality and readmission rate among anxious and/or depressive COPD patients increases during the 30 days following hospitalisation ${ }^{9}$. The presence of depression has prognostic value, as shown in a study in COPD patients hospitalised for exacerbation ${ }^{10}$. Mortality following a COPD exacerbation was greater among the depressive patients.

The present study uses a large number of patients and a control group to investigate whether depression occurs more often in patients with mild to moderate COPD and those with severe COPD than in controls, and the aspects of COPD particularly related to depression.

The study was approved by the medical ethics committee of the Bundelkhand Government Medical College ,Sagar,Madhya Pardesh. 


\section{Method}

All patients who visited the Bundelkhand Government Medical college and Hospital from January 2010 to March 2013 for treatment of COPD were considered as possible study subjects. First we screened patients by reviewing their charts and then evaluated them for the inclusion criteria. Patients who satisfied the criteria and agreed to participate were then surveyed.

\section{Study Population}

The inclusion criteria were:

- COPD diagnosis as defined by the Global Initiative for Chronic Obstructive Lung Disease (GOLD) 1 (spirometry was newly performed at this time)

- Stable medical condition, without exacerbation or infection in the preceding 2 weeks

- No orthopedic problem interfering with the 6-min walk test

- $\mathrm{S}_{\mathrm{pO} 2} \geq 90 \%$ on ambient air

- Able to safely complete the 6-min walk test

- Not currently taking an antidepressant (the degree of depression may be affected by antidepressant; depressed patients not taking antidepressants were not excluded)

- Absence of severe disease such as active malignancy or human immunodeficiency virus, which may influence the degree of depression.

All eligible subjects $(\mathrm{n}=1106)$ who were willing to participate underwent a lung function test to confirm a diagnosis of COPD and filled in a questionnaire between January 2011 and March 2013 (n=659, response $60 \%)$. Patients who met the criteria for COPD were included $(\mathrm{n}=162)$. Lung function data and questionnaire data were obtained on the same day.

\section{Selection Of Control}

A random sample of 676 subjects was taken from 13 general practices who were not diagnosed by the GP as having asthma or COPD and who were aged 40 years or older.All those controls were excluded persons with poor cognitive functioning $(n=26)$ or with an end stage disease

$(\mathrm{n}=8)$. All eligible controls $(\mathrm{n}=642)$ who were willing to participate filled in a questionnaire between January 2011 and March 2013 ( $\mathrm{n}=445$, response 69\%). In addition, all controls with missing data on more than half of the items of the measure for depression were excluded $(n=62)$ as well as controls with self-reported obstructive pulmonary disease $(\mathrm{n}=24)$.

\section{Measurement of depression}

The Centers for Epidemiologic Studies Depression (CES-D) scale was used to assess the presence of depressive symptoms. Those with a score of 16 or higher on the CES-D were considered possible cases for depression. The CES-D is validated and widely used in epidemiological studies as an indicator for clinical depression in populations ${ }^{11}$.In case less than half of the items on the CES-D were incomplete, missing data were replaced by the mean scores of the valid data of each participant.

To determine the presence of comorbid diseases, all participants were asked to complete a questionnaire on chronic diseases.The following diseases were listed: locomotive diseases (rheumatoid arthritis, arthrosis, slipped disc, disorder of the back for $>3$ months), hypertension, serious heart diseases or myocardial infarction, sinusitis, migraine, dizziness with falling, ulcer stomach/duodenum, cancer, atherosclerosis, thyroid diseases, diabetes, serious intestinal diseases for $>3$ months, serious skin diseases, gall bladder diseases, stroke, chronic cystitis, kidney stones, thrombosis, epilepsy, liver diseases, and renal diseases.

In addition, information on the following variables was obtained by questionnaire: sex, age, highest form of education received (low level: primary school, lower vocational training, school for lower general secondary education; high level: pre-university education, high vocational training or university).

Symptoms and physical functioning were assessed using the symptoms and activity components of the St George's Respiratory Questionnaire (SGRQ) ${ }^{12}$.The symptoms component is concerned with the frequency and severity of respiratory symptoms, and the activity component is concerned with activities that are limited by breathlessness.

\section{Analysis of data}

The prevalence of depression was determined by calculating the percentage of patients and controls with a score of 16 or higher on the CES-D. To determine whether the prevalence of depression was higher in patients than in controls, logistic regression analyses were performed in which the results were adjusted for demographic variables and comorbidity. In this model the dependent variable was the score on the CES-D (16 or higher/lower than 16) and the independent variable was the research group (patient/control). Age, sex, 
education, type of insurance, living conditions, and comorbidity were included as covariates. All analyses were carried out using SPSS 8.0.2 for Windows.

\section{General characteristics}

\section{Results}

A total of 162 patients with COPD and 359 controls were included in the study. Their characteristics are shown in table 1. Sixty of the patients had an $\mathrm{FEV}_{1}<50 \%$ of the predicted value $(37.0 \%)$ and thus suffered from severe airway obstruction; 102 patients had an $\mathrm{FEV}_{1} 50-80 \%$ of the predicted value (63.0\%). In both patient groups the majority were men $(73.3 \%$,

$70.6 \%)$, had a low level of education $(88.1 \%, 85.0 \%)$, and had other chronic diseases $(65.5 \%, 71.0 \%)$. Fewer of the controls were men (40.4\%), had a low level of education (80.1\%), or had chronic diseases $(57.0 \%)$. The mean age of controls (65.6 years) was comparable to that of patients (67.8, 66.2 years).

Table 1:General characteristics of patients and controls

\begin{tabular}{|l|l|l|l|}
\hline & $\begin{array}{l}\text { COPD patients }\left(\mathrm{FEV}_{\mathbf{1}}<\mathbf{5 0 \%}\right) \\
(\mathbf{n = 6 0})\end{array}$ & $\begin{array}{l}\text { COPD patients }\left(\mathrm{FEV}_{1} \mathbf{5 0}-\mathbf{8 0} \%\right) \\
(\mathbf{n = 1 0 2})\end{array}$ & $\begin{array}{l}\text { Controls } \\
(\mathbf{n = 3 5 9})\end{array}$ \\
\hline Male sex & $44(73.3 \%)$ & $72(70.6 \%)$ & $145(40.4 \%)$ \\
\hline Low education & $52(88.1 \%)$ & $85(85.0 \%)$ & $274(80.1 \%)$ \\
\hline Living alone & $10(16.7 \%)$ & $30(29.4 \%)$ & $92(25.8 \%)$ \\
\hline Comorbidity & $36(65.5 \%)$ & $66(71.0 \%)$ & $179(57.0 \%)$ \\
\hline Mean (SD) age (years) & $67.8(8.7)$ & $66.2(10.3)$ & $65.6(12.8)$ \\
\hline $\begin{array}{l}\text { Mean (SD) reversibility } \\
\text { FEV }_{1}(\%)\end{array}$ & $4.2(4.1)$ & $5.6(3.9)$ & - \\
\hline
\end{tabular}

\section{Prevalence of depression}

In table 2 the results are presented on the prevalence of depression in patients with COPD and in controls. In the COPD patients as a whole, $21.6 \%$ had a score of 16 or more on the CES-D scale compared with $25.0 \%$ of patients with severe COPD $\left(\mathrm{FEV}_{1}<50 \%\right), 19.6 \%$ of those with mild to moderate COPD $\left(\mathrm{FEV}_{1} 50\right.$ $80 \%$ ), and $17.5 \%$ of the controls. As demographic variables and comorbidity were thought to be important prognostic variables which could confound the differences in the prevalence of depression between patients and controls, the results were adjusted for these variables. In the multivariate analysis there appeared to be no risk for depression in the total group of COPD patients (OR 1.5, 95\% CI 0.8 to 2.6) or in the subgroup of patients with mild to moderate COPD (OR 1.1, 95\% CI 0.5 to 2.1), but patients with severe COPD had a 2.5 times greater risk for depression than controls (OR 2.5, 95\% CI 1.2 to 5.4).

Table 2: Prevalence of depression in patients with COPD compared with controls

\begin{tabular}{|c|c|c|c|}
\hline & $\mathbf{n}$ & CES-D $\geq 16$ & Adjusted OR (95\% CI) \\
\hline \multicolumn{4}{|c|}{ CES-D=Centers for Epidemiologic Studies Depression scale. } \\
\hline \multicolumn{4}{|c|}{$\begin{array}{l}\text { Univariate results and results adjusted for sex, age, education, health insurance, living situation, and comorbidity } \\
\text { (logistic regression analysis). }\end{array}$} \\
\hline COPD (whole group) & 162 & $35(21.6 \%)$ & $1.5(0.8$ to 2.6$)$ \\
\hline Severe COPD $\left(\mathrm{FEV}_{1}<50 \%\right.$ predicted $)$ & 60 & $15(25.0 \%)$ & $2.5(1.2$ to 5.4$)$ \\
\hline Mild to moderate COPD ( $\mathrm{FEV}_{1} 50-80 \%$ predicted) & 102 & $20(19.6 \%)$ & $1.1(0.5$ to 2.1$)$ \\
\hline Controls & 359 & $63(17.5 \%)$ & 1.0 \\
\hline
\end{tabular}

\section{Determinants of depression}

The prevalence of depression was also calculated in several subgroups of COPD patients (table 3). In these subgroups the prevalence of depression ranged from 15.2\% (absence of comorbidity) to $50.0 \%$ (severe impaired physical functioning). Depression also occurred often in patients with a reversibility in $\mathrm{FEV}_{1}$ of $\leq 1.1 \%$ (44.8\%), in patients with a score on the symptoms dimension of the SGRQ of $\leq 71.98$ (39.4\%), and in patients who lived alone (37.5\%). 
Table 3:Relationship between demographic and disease-related variables and depression (CES-D) in patients with COPD ( $\mathrm{n}=162)$ : prevalence in subgroups and logistic regression analysis

\begin{tabular}{|c|c|c|c|c|}
\hline & $\mathbf{n}$ & CES-D $\geq 16$ & $\begin{array}{l}\text { Crude OR }(95 \% \\
\text { CI) }\end{array}$ & $\begin{array}{l}\text { Adjusted OR } \dagger(95 \% \\
\text { CI) }\end{array}$ \\
\hline \multicolumn{5}{|l|}{${ }^{*} \mathrm{p}<0.01\left(\chi^{2}\right.$ test $)$} \\
\hline \multicolumn{5}{|l|}{$\dagger$ Adjusted for all other variables. } \\
\hline \multicolumn{5}{|c|}{$\$$ Score $=71.98$ on symptoms dimension SGRQ (mean $+1 \mathrm{SD})$} \\
\hline \multicolumn{5}{|c|}{$\S$ Score $=68.69$ on activities dimension SGRQ (mean + 1 SD). } \\
\hline$\geq 65$ years & 99 & $17(17.2 \%)$ & $0.5(0.2$ to 1.1$)$ & $0.7(0.2$ to 1.9$)$ \\
\hline$<65$ years & 63 & $18(28.6 \%)$ & 1.0 & 1.0 \\
\hline Men & 116 & $21(18.1 \%)$ & $0.5(0.2$ to 1.1$)$ & $0.8(0.3$ to 2.2$)$ \\
\hline Women & 46 & $14(30.4 \%)$ & 1.0 & 1.0 \\
\hline Low education & 137 & $29(21.2 \%)$ & $0.9(0.3$ to 2.7$)$ & $0.8(0.2$ to 3.0$)$ \\
\hline High education & 22 & $5(22.7 \%)$ & 1.0 & 1.0 \\
\hline Living alone & 40 & \begin{tabular}{|l|l|}
15 \\
$(37.5 \%)^{*}$
\end{tabular} & $3.1(1.4$ to 6.8$)$ & $2.8(1.0$ to 7.8$)$ \\
\hline Living with others & 122 & $20(16.4 \%)$ & 1.0 & 1.0 \\
\hline Presence comorbidity & 102 & $25(24.5 \%)$ & $1.8(0.7$ to 4.5$)$ & $2.4(0.7$ to 8.1$)$ \\
\hline Absence comorbidity & 46 & $7(15.2 \%)$ & 1.0 & 1.0 \\
\hline $\mathrm{FEV}_{1}<50 \%$ predicted & 60 & $15(25.0 \%)$ & $1.4(0.6$ to 2.9$)$ & $0.8(0.3$ to 2.5$)$ \\
\hline $\mathrm{FEV}_{1} \geq 50 \%$ predicted & 102 & $20(19.6 \%)$ & 1.0 & 1.0 \\
\hline Reversibility $\leq 1.1 \%$ & 29 & $\begin{array}{l}13 \\
(44.8 \%)^{*}\end{array}$ & $4.1(1.7$ to 9.7$)$ & $3.7(1.3$ to 11.0$)$ \\
\hline Reversibility $1.1-12 \%$ & 133 & $22(16.5 \%)$ & 1.0 & 1.0 \\
\hline Severe symptoms & 33 & $\begin{array}{l}13 \\
(39.4 \%)^{*}\end{array}$ & $3.2(1.4$ to 7.3$)$ & 2.8 (0.9 to 8.6$)$ \\
\hline Mild to moderate symptoms & 129 & $22(17.1 \%)$ & 1.0 & 1.0 \\
\hline Severe impaired physical function§ & 20 & $\begin{array}{l}10 \\
(50.0 \%)^{*}\end{array}$ & $4.7(1.8$ to 12.4$)$ & $5.6(1.6$ to 19.9$)$ \\
\hline $\begin{array}{l}\text { Mild to moderate impaired physical } \\
\text { function }\end{array}$ & 142 & $25(17.6 \%)$ & 1.0 & 1.0 \\
\hline
\end{tabular}

\section{Discussion}

In this study we found that the prevalence of depression in COPD patients with severe airways obstruction $\left(\mathrm{FEV}_{1}<50 \%\right)$ was $25 \%$ and that they had a 2.5 times greater risk of depression than controls who were comparable for demographic variables and the presence of comorbidity. In patients with mild to moderate COPD no increased risk for depression was seen. We also found that living alone, reversibility in $\mathrm{FEV}_{1} \%$ predicted, respiratory symptoms, and physical impairment were related to depression in patients with COPD, whereas age, sex, insurance type, education, $\mathrm{FEV}_{1}$, and comorbidity were not.

The first was conducted by Light evaluating the association between physical factors and depression in $1985^{13}$.Until 2007, most studies denied an association between depression and physical measurements of COPD. In contrast, most studies since 2008 have affirmed a positive association between depression and physical measurements of COPD. That lack of concordance might be owing to the wide variation in nationality, measurement tools, study design, and diagnostic criteria ${ }^{14}$. The homogenous severity of COPD makes it especially difficult to detect a relationship. For example, most studies found a significant relationship between 
dyspnea and depression; however, some studies conducted with subjects who had relatively mild obstruction did not find an association ${ }^{15}$.

The associations between depression and some physical parameters are indisputable, but the interpretation is difficult. The simplest explanation is that depression is caused by COPD symptoms or limited quality of life. Another explanation is that depression makes physical signs and symptoms worse. The following evidence supports this hypothesis: subjective sensation of dyspnea increased with depression, even with normal lung function ${ }^{16}$, and $6 \mathrm{MWD}$ depends on both physical and psychological factors ${ }^{17,18}$. The other explanation is that systemic inflammation lowers both physical and mental status. There is a recent accumulation of evidence that somatic factors such as inflammation cytokines are also related to depression in COPD patients ${ }^{19,20}$. Further research is expected to clarify the interaction between physical factors and depression.

The CES-D scale which we used as a measure for depression is not designed to determine the presence of clinical depression, but rather the presence of depressive symptoms ${ }^{21}$.Patients with a score of ${ }^{16}$ or higher are considered possible cases. The percentage of patients with actual clinical depression may thus have been lower than was found in this study. . Furthermore, an overestimation of actual cases of depression does not influence the estimated risk of depression in patients with COPD as overestimation will be the same in patients and in controls.

In previous studies the prevalence of depression in patients with COPD ranged from 6\% to $46 \%$ 22-26, 27${ }^{30}$ This variation in prevalence can be partly attributed to the use of different measures for depression. In the one study that also used the CES-D scale, a prevalence of depression of $29 \%$ was found ${ }^{27}$. The reason why depression occurred more often in this study than in our study may be that it included patients with more severe airways obstruction who were eligible for a rehabilitation programme. As disease and demographic characteristics of the patient population included in the study also influence the extent to which depression occurs, the prevalence of depression in patients with COPD does not exist. It is therefore difficult to compare prevalence rates from studies that included different populations.

Since previous studies suffered from several methodological problems such as small sample sizes and the absence of proper control groups, it remained inconclusive whether patients with COPD were more at risk than controls for the development of depression ${ }^{26}$.Furthermore, many studies only included patients with a restricted range of pulmonary function. The results of these studies are only valid for specific patients-for example, those receiving oxygen therapy ${ }^{2}$ or with an exacerbation30. Another reason for conflicting results between studies is that, in several studies, patients and controls were not comparable with respect to important prognostic factors. In some studies patients and control subjects were only matched on age and sex ${ }^{24-26}$ while other studies also matched on education and social class ${ }^{31}$. Furthermore, in some studies patients with comorbidity were exclude ${ }^{25,25,28,30}$ while in others these patients were included ${ }^{32}$.

Our study did not suffer from these methodological problems as we were able to include a large sample of COPD patients with a broad range of severity of disease and a large number of controls. Furthermore, as we adjusted our results for the presence of chronic disease, it became clear that comorbidity, which frequently occurs in patients with COPD, is not responsible for the increased risk of depression in these patients.

\section{Limitations}

This study had some limitations.

- More than 90\% of COPD patients in our study have emphysema. In Western countries, emphysema type is less common.

- The majority of subjects were male.

- There were several confounders, such as socio-economic status.

\section{Conclusion}

In conclusion, depressive symptoms are common in patients with COPD and those with severe COPD have a 2.5 times greater risk of developing depression than controls. As depression is a disorder which remains easily undiagnosed due to underrepresentation and because the symptoms are not very specific, it is important to consider this disorder in patients with COPD.

\section{References}

[1]. Rabe K F et al Global strategy for the diagnosis, management, and prevention of chronic obstructive pulmonary disease: GOLD executive summary. Am J Respir Crit Care Med 2007;176(6):532-555.

[2]. Mannino DM et alObstructive and restrictive lung disease and markers of inflammation: data from the Third National Health and Nutrition Examination. Am J Med 2003;114(9):758-762.

[3]. $\quad \mathrm{Ng} \mathrm{TP}$ et al Depressive symptoms and chronic obstructive pulmonary disease: effect on mortality, hospital readmission, symptom burden, functional status, and quality of life. Arch Intern Med 2007;167(1):60-67.

[4]. Dowson CA et al Psychopathology and illness beliefs influence COPD self-management. J Psychosom Res2004;56(3):333-340.

[5]. Norwood R et al Current perspectives on management of co-morbid depression in COPD. COPD 2005;2(1):185-193

[6]. Wilson I et al Depression in the patient with COPD. Int J Chron Obstruct Pulmon Dis 2006;1(1):61-64. 
[7]. Regvat $\mathbf{J}$ et al Anxiety and depression during hospital treatment of exacerbation of chronic obstructive pulmonary disease. $\mathrm{J}$ Int Med Res 2011; 39: 1028-1038.

[8]. Spitzer C et al Mental health problems, obstructive lung disease and lung function: findings from the general population. J Psychosom Res 2011; 71: 174-179.

[9]. Schneider C et al COPD and the risk of depression. Chest2010; 137: 341-347.

[10]. Kunik M E et al Surprisingly high prevalence of anxiety and depression in chronic breathing disorders. Chest 2005; 127: 12051211.

[11]. Van Manen JG et al Risk of depression in patients with chronic obstructive pulmonary disease and its determinants. Thorax 2002; 57: 412-416.

[12]. Abrams TE et al Acute exacerbations of chronic obstructive pulmonary disease and the effect of existing psychiatric comorbidity on subsequent mortality. Psychosomatics 2011; 52: 441-449.

[13]. Ng TP et al Depressive symptoms and chronic obstructive pulmonary disease. Arch Intern Med 2007; 167: 60-67.

[14]. Ensel WM. Measuring depression: the CES-D scale. In: Lin N, Dean A, Ensel WM, eds. Social support, life events and depression. Orlando: Academic Press, 1986: 51-70.

[15]. Jones PW, Quirk FH, Baveystock CM. The St George's respiratory questionnaire. Respir Med1991;85:25-31

[16]. Çalikoglu M et al . Pulmonary muscle strength, pulmonary function tests, and dyspnea in women with major depression. J Womens Health (Larchmt) 2004;13(1):93-98.

[17]. Spruit MA, et al Determinants of poor 6-min walking distance in patients with COPD: the

[18]. ECLIPSE cohort. Respir Med 2010;104(6):849-857.

[19]. Lord SR et al. Physiologic, psychologic, and health predictors of 6-minute walk performance in older people. Arch Phys Med Rehabil2002;83(7):907-911.

[20]. Al-shair K et al Biomarkers of systemic inflammation and depression and fatigue in moderate clinically stable COPD. Respir Res 2011;12:3.

[21]. Eagan TM, et al.Systemic inflammatory markers in COPD: results from the Bergen COPD Cohort Study. Eur Respir J 2010;35(3):540-548.

[22]. Ensel WM. Measuring depression: the CES-D scale. In: Lin N, Dean A, Ensel WM, eds. Social support, life events and depression. Orlando: Academic Press, 1986: 51-70.

[23]. McSweeny AJ, Grant I, Heaton RK, et al. Life quality of patients with chronic obstructive pulmonary disease. Arch Intern Med1982;142:473-8.

[24]. Prigatano GP, Wright EC, Levin D. Quality of life and its predictors in patients with mild hypoxemia and chronic obstructive pulmonary disease. Arch Intern Med1984;144:1613-9.

[25]. Yohannes AM, Roomi J, Baldwin RC, et al. Depression in elderly outpatients with disabling chronic obstructive pulmonary disease. Age Ageing1998;27:155-60

[26]. Engstrouml;m C, Persson L, Larsson S, et al. Functional status and well being in chronic obstructive pulmonary disease with regard to clinical parameters and smoking: a descriptive and comparative study. Thorax1996;51:825-30.

[27]. Isoaho R, Keistinen T, Laippala P, et al. Chronic obstructive pulmonary disease and symptoms related to depression in elderly persons. Psychol Rep1995;76:287-97.

[28]. Toshima MT, Blumberg E, Ries AL, et al. Does rehabilitation reduce depression in patients with chronic obstructive pulmonary diseaseJ Cardiopulmonary Rehabil1992;12:261-9.

[29]. Light RW, Merrill EJ, Despars JA, et al. Prevalence of depression and anxiety in patients with COPD. Relationship to functional capacity. Chest1985;87:35-8.

[30]. Karajgi B, Rifkin A, Doddi S. The prevalence of anxiety disorders in patients with chronic obstructive pulmonary disease. Am J Psychiatry 1990;147:200-1

[31]. Gordon GH, Michiels TM, Mahutte CK, et al. Effect of desipramine on control of ventilation and depression scores in patients with severe chronic obstructive pulmonary disease. Psychiatry Res1985;15:25-32.

[32]. Jones PW, Baveystock CM, Littlejohns P. Relationships between general health measured with the sickness impact profile and respiratory symptoms, physiological measures, and mood in patients with chronic airflow limitation. Am Rev Respir Dis 1989; 140:1538-43

[33]. Yellowlees PM. The treatment of psychiatric disorders in patients with chronic airways obstruction. Med J Aust1987;147:349-52 